\title{
Atributos químicos, produção e qualidade do capim braquiária em solos corrigidos com calcário e escória silicatada
}

\author{
Graciele Sarante Santana ${ }^{1}$, Isabela Miyahira Morita², Pedro Paulo Magalhães Bianchi ${ }^{3}$ Francisco Maximino \\ Fernandes ${ }^{4}$, Olair José Isepon ${ }^{5}$
}

\section{RESUMO}

As pastagens constituem a base dos sistemas de produção de bovinos, o que evidencia sua importância e a necessidade de outras práticas de manejo que resultem em maior eficiência desses sistemas. Assim, este trabalho teve como objetivo avaliar os atributos químicos do solo ( $\mathrm{pH}, \mathrm{Ca}, \mathrm{Mg}$ e $\mathrm{H}+\mathrm{Al})$, o potencial produtivo e a composição química do capim braquiária (Brachiaria decumbens Stapf) em solo corrigido com diferentes doses de calcário e escória silicatada. O experimento foi conduzido em ambiente protegido no período de 2006/2007, na UNESP de Ilha Solteira. Foram testadas cinco doses de calcário e escória silicatada, 0,0; 0,5; 1,0; 1,5; 2,0 vezes a dose recomendada. O delineamento experimental foi inteiramente casualizado, com quatro repetições. Avaliou-se a composição química do solo após incubação dos corretivos, o perfilhamento, a matéria seca, proteína, FDN (fibra em detergente neutro) e FDA (fibra em detergente ácido). Ambos os corretivos proporcionaram ao solo efeito positivo em relação ao pH e teores de cálcio e magnésio. As variáveis matéria seca e FDA não foram influenciadas significativamente pelos tipos e doses de corretivos.

Palavras-chave: Brachiaria decumbens Stapf, corretivo de acidez, matéria seca, perfilhamento.

\section{ABSTRACT}

\section{Chemical attributes, production and quality of signal grass in soils amended with limestone and calcium silicate slag}

Pastures are the basis of cattle production systems, evidencing their importance and the need for other management practices that result in higher efficiency of these systems. This study aimed to evaluate the soil chemical properties ( $\mathrm{pH}, \mathrm{Ca}, \mathrm{Mg}$ and $\mathrm{H}+\mathrm{Al}$ ), the potential production and the chemical composition of signal grass (Brachiaria decumbens Stapf) in soil amended with different limestone doses and calcium silicate slag. The experiment was carried out in a greenhouse, in the period 2006/2007, at the Universidade Estadual Paulista, Ilha Solteira-SP. Five doses of limestone and calcium silicate slag were tested, $0.0 ; 0.5 ; 1.0 ; 1.5 ; 2.0$ times the recommended dose. A complete randomized design was used with four repetitions. Soil chemical composition was evaluated after incubation with the amendment, tillering, dry matter, protein, NDF (neutral detergent fiber) and ADF (acid detergent fiber). Both amendments provided to the soil positive effect in relation to the $\mathrm{pH}$ and content of calcium and magnesium. The variables dry matter and ADF were not significantly influenced by the types and doses of the amendments.

Key words: Acidity correction, Brachiaria decumbens Stapf, dry matter, tillering.

\footnotetext{
Recebido para publicação em abril de 2009 e aprovado em abril de 2010

${ }^{1}$ Engenheira Agrônoma. Universidade Federal do Rio Grande do Sul, Departamento de Ciência do Solo, Campus Universitário, 91530-080, Porto Alegre, Rio Grande do Sul, Brasil. gsarante@yahoo.com.br

${ }^{2}$ Acadêmica em Agronomia. Universidade Estadual Paulista Júlio de Mesquita Filho, UNESP, Departamento de Biologia e Zootecnia, Av. Brasil, 56, Caixa-Postal 31, Centro, 15385000, lha Solteira, São Paulo, Brasil. isabelamorita@uol.com.br

${ }^{3}$ Acadêmico em Zootecnia. Universidade Estadual Paulista Júlio de Mesquita Filho, UNESP, Departamento de Biologia e Zootecnia, Av. Brasil, 56, Caixa-Postal 31, Centro, 15385000, lha Solteira, São Paulo, Brasil. pedro_tanabi@hotmail.com

${ }^{4}$ Engenheiro Agrônomo, Doutor. Universidade Estadual Paulista Júlio de Mesquita Filho, UNESP, Departamento de Fitossanidade, Av. Brasil, 56, Caixa-Postal 31, Centro, 15385000, lha Solteira, São Paulo, Brasil. maximino@agr.feis.unesp.br

${ }^{5}$ Zootecnista, Doutor. Universidade Estadual Paulista Júlio de Mesquita Filho, UNESP, Departamento de Biologia e Zootecnia, Av. Brasil, 56, Caixa-Postal 31, Centro, 15385000, lha Solteira, São Paulo, Brasil. isepon@bio.feis.unesp.br
} 


\section{INTRODUÇÃO}

A produção animal em sistemas de pastagem apresenta baixo custo econômico e rendimento na produção quando comparado a sistemas que visam à produção por confinamento, e alimentação à base de concentrados. Assim, para melhor eficiência desse sistema, práticas de manejo que visam ao maior desenvolvimento das pastagens são necessárias.

Uma das práticas agrícolas que pode ser utilizada, porém de pouco estudo em pastagem, é a correção de acidez do solo (Mesquita et al., 2002; Oliveira et al., 2007). Grande parte dos solos utilizados pela agropecuária brasileira apresenta elevada acidez. Esse fato, relacionado a outros, resulta em baixa produtividade das culturas, sendo assim necessário a aplicação de corretivos para elevar o seu $\mathrm{pH}$, neutralizar os efeitos dos elementos tóxicos, fornecer cálcio e magnésio como nutrientes e aumentar a produtividade das culturas (Veloso, 1992).

Na maioria das propriedades dedicadas à pecuária no Brasil, a exploração das pastagens é feita com pouco ou nenhum uso de corretivos e fertilizantes em sistemas com baixa carga animal. Esse tipo de manejo por longos períodos geralmente leva à diminuição da fertilidade do solo e à degradação das pastagens (Cantarella et al., 2002).

O calcário é o corretivo de acidez do solo mais utilizado no Brasil. No entanto, existem outros materiais corretivos como os resíduos siderúrgicos que possuem a mesma finalidade e tem-se mostrado alternativa viável, destacando-se a escória silicatada (Amaral et al., 1994). A escória silicatada ou de siderurgia é um subproduto obtido a partir da sílica do minério de ferro que reage com cálcio do calcário em alto forno, resultando no silicato de cálcio com impurezas (Malavolta, 1981). As escórias em geral apresentam o ânion silicato que corrige a acidez do solo, embora com ação mais lenta quando comparado ao calcário (Prado \& Fernandes, 2000). Além do efeito na correção de acidez do solo, a escória tem efeito positivo no fornecimento de silício às plantas (Barbosa Filho et al., 2004), podendo ocasionar alterações nas concentrações de fibra na planta. Vilela et al. (2007) observaram aumento de fibra de detergente neutro e maior digestibilidade da matéria seca da forragem com a aplicação de silicato. A disponibilidade de fósforo na solução do solo também pode ser afetada por meio da liberação dos íons solúveis de silicato durante o processo de dissolução no solo, os quais são fixados pelos óxidos e hidróxidos de Fe e Al, competindo com íons fosfatos pelos sítios de troca (Souza \& Yasuda, 1994).

As plantas forrageiras possuem diferente comportamento quanto à acidez do solo, haja vista que algumas conseguem se desenvolver e se estabelecer em solos ácidos. No entanto, outras necessitam de solos com pH mais elevado para apresentar boa produção. O capim-braquiária (Brachiaria decumbens) constitui umas das forrageiras que se adapta a condições adversas, porém com baixa produtividade. Segundo Kissmann (1997), o capim Brachiaria decumbens trata-se de excelente forrageira perene e com grande produção de massa foliar de boa qualidade, resistente ao pastejo e ao pisoteio e que protege o solo contra erosão.

Assim, este trabalho foi conduzido com o objetivo de avaliar alguns atributos químicos do solo, perfilhamento, matéria seca e composição bromatológica do capimbraquiária, em solo corrigido com diferentes doses de calcário e escória silicatada.

\section{MATERIAL E MÉTODOS}

O experimento foi conduzido em ambiente protegido (estufa), na Faculdade de Engenharia, Campus II, UNESP - Ilha Solteira. O solo utilizado foi classificado como Latossolo, cujas características químicas segundo Raij \& Quaggio (1983), na camada 0-20 cm, foram: P (mg dm$\left.{ }^{-3}\right)$ : 8; M.O. $\left(\mathrm{g} \mathrm{dm}^{-3}\right)$ : 23; $\mathrm{pH} \mathrm{CaCl}_{2}: 4,7 ; \mathrm{K}^{+}\left(\mathrm{mmol}_{\mathrm{c}} \mathrm{dm}^{-3}\right): 0,8 ; \mathrm{Ca}^{+2}$ $\left(\mathrm{mmol}_{\mathrm{c}} \mathrm{dm}^{-3}\right): 9 ; \mathrm{Mg}^{+2}\left(\mathrm{mmol}_{\mathrm{c}} \mathrm{dm}^{-3}\right): 6 ; \mathrm{H}+\mathrm{Al}\left(\mathrm{mmol}_{\mathrm{c}} \mathrm{dm}^{-3}\right)$ : 31 e CTC (mmol $\left.\mathrm{dm}^{-3}\right)$ : 46,6; V(\%): 34 .

O delineamento experimental foi inteiramente casualizado, em esquema fatorial 2 x 5 e quatro repetições, sendo dois corretivos de acidez e cinco doses de corretivos. Os corretivos utilizados foram calcário dolomítico (39\% CaO e 13\% MgO) e escória silicatada (25,2\% CaO e 2,5\% MgO) com PRNT de 91,5\% e 59,1\%, respectivamente. As doses dos corretivos foram definidas com base na recomendação para a cultura a partir da elevação da saturação por bases do solo variando com a espécie forrageira (Werner et al., 1997), sendo utilizadas 0,$0 ; 0,5 ; 1,0 ; 1,5$ e 2,0 vezes a dose recomendada para cultura (1,8 t ha-1 de calcário e 2,8 t ha-1 de escória silicatada), correspondendo a 0,$0 ; 2,7 ; 5,4 ; 8,1 ; 10,8$ g de calcário e 0,0; 4,2; 8,4; 12,6; 16,8 g de escória silicatada por vaso com $6 \mathrm{dm}^{-3}$ de solo.

Inicialmente o solo foi peneirado, e os corretivos (PRNT: calcário 91,5\% e escória silicatada 59,1\%), nas suas respectivas doses, foram misturados ao solo e colocados nos vasos. A umidade foi mantida a aproximadamente $70 \%$ da CRA (capacidade de retenção de água) por 50 dias. Para determinação da CRA foram utilizados cadinhos de Gooch, previamente saturados em água, secos e pesados. Aos cadinhos foram adicionados $10 \mathrm{~g}$ de solo e submersos em água por um período de 12 horas. Após, os cadinhos foram retirados da água e deixados escorrer por 48 horas e então pesados.

Duas semanas antes da semeadura a irrigação foi cessada para realizar uma adubação fosfatada. Para isso utilizou-se oito vezes a dose recomendada de fósforo (60 kg 
ha-1 de $\mathrm{P}_{2} \mathrm{O}_{5}$ ), pois de acordo com Fageria et al. (1982), os níveis ótimos para a cultura do arroz, também uma gramínea, cultivado em casa de vegetação correspondem, aproximadamente, a oito vezes o nível de adubação recomendada para as condições de campo. A fonte utilizada foi o superfosfato simples $\left(18 \% \mathrm{P}_{2} \mathrm{O}_{5}\right)$. Antes da adubação fosfatada foram coletadas amostras de solo (todos os vasos) para analisar o efeito dos corretivos no solo antes e após a implantação da cultura (pH, Ca, $\mathrm{Mg}$ e H+Al). A semeadura foi realizada no dia seguinte à adubação com fósforo, tendo sido semeadas aproximadamente 30 sementes de braquiária (Brachiaria decumbens) por vaso. A germinação ocorreu três dias após a semeadura. Entre o $10^{\circ}$ e o $20^{\circ}$ dia após a emergência foram realizados desbastes periódicos até atingir cinco plantas de braquiária por vaso.

Foi feita adubação de cobertura aos 25 dias após a germinação com nitrogênio e potássio equivalentes a 30 $\mathrm{kg} \mathrm{ha}^{-1} \mathrm{~N} \mathrm{e}_{2} \mathrm{O}$, utilizando-se como fonte de $\mathrm{N}$, a uréia e fonte de K, o cloreto de potássio. Devido à incidência de lagarta do cartucho (Spodoptera frugiperda), tripes e cigarrinha das pastagens, foi necessária a aplicação dos inseticidas Perfekthion e Horsban 480 CE aos 37 e 73 dias, respectivamente, após a germinação. Foram realizados três cortes do capim, aos 51, 87 e 119 dias após a germinação. Esse material foi seco a $60^{\circ} \mathrm{C}$ até peso constante e depois pesado. Após cada corte foram realizadas adubações com nitrogênio e potássio equivalentes a 60 $\mathrm{kg} \mathrm{ha}^{-1} \mathrm{~N}$ e $30 \mathrm{~kg} \mathrm{ha}^{-1} \mathrm{~K}_{2} \mathrm{O}$ no primeiro e terceiro cortes; $30 \mathrm{~kg} \mathrm{ha}^{-1} \mathrm{~N}$ e $30 \mathrm{~kg} \mathrm{ha}^{-1} \mathrm{~K}_{2} \mathrm{O}$ no segundo corte. Foram realizadas oito contagens de perfilhos, aos 18, 25, 32, 39, 46, 71, 93 e 119 dias após a germinação. O número de perfilhos por planta antes do primeiro corte foi definido contando todos os perfilhos das cinco plantas e depois esse valor foi dividido pelo número de plantas com perfilhos. Após os cortes, o número de perfilho foi determinado contando os perfilhos de uma única planta escolhida aleatoriamente.

Os teores de matéria seca (MS), proteína bruta (PB), fibra em detergente neutro (FDN) e fibra em detergente ácido (FDA), nos três cortes, foram determinados no Laboratório de Bromatologia do Departamento de Biologia e Zootecnia.

Os dados coletados foram submetidos à análise de variância e teste $\mathrm{F}$ e as médias dos tratamentos foram comparadas aplicando-se o teste de Tukey, a 5\% de probabilidade. A análise estatística foi realizada utilizando-se o programa estatístico SANEST.

\section{RESULTADOS E DISCUSSÃO}

Verificou-se pela análise de solo que não houve diferença significativa dos corretivos na correção da acidez potencial $(\mathrm{H}+\mathrm{Al})$. No entanto, a interação corretivo x doses foi significativa, ocorrendo decréscimo do $\mathrm{H}+\mathrm{Al}$ no solo em função do aumento das doses de calcário e escória silicatada, ajustando-se as equações linear e quadrática $y=37,650-0,7200 x$ e $y=32,014+0,652 x-0,048 x^{2}$, respectivamente (Figura 1). De modo geral, observou-se efeito favorável das duas fontes de corretivos para as variáveis $\mathrm{pH}, \mathrm{K}, \mathrm{Ca}, \mathrm{Mg}$ e ( $\mathrm{H}+\mathrm{Al})$ comparativamente à análise química inicial (Tabela 1). Prado (2000) avaliou o efeito dos tratamentos com calcário e escória silicatada nos atributos químicos do solo, em cana-de-açúcar, e observou que tanto o calcário como a escória silicatada influenciaram as propriedades químicas do solo, aumentando o $\mathrm{pH}$ e os teores de cálcio e magnésio. Resultados semelhantes foram verificados por Pereira (1978) e Piau (1995), que avaliaram a escória e calcário em dois solos, e observaram que ambos corretivos apresentaram comportamento semelhante quanto à correção da acidez com incrementos nos teores de cálcio e magnésio.

Houve aumento do $\mathrm{pH}$ em todos tratamentos, sendo que o corretivo calcário proporcionou maior valor do $\mathrm{pH}$ quando comparado com a escória silicatada (Tabela 1). Esse resultado pode estar relacionado ao maior PRNT do calcário e confirma os obtidos por Fortes (1993), que verificaram ineficiência da aplicação de escória baseado no poder de neutralizadção (PN) para a correção do solo comparativamente ao calcário. Prado \& Fernandes (2000), estudando o efeito do calcário e da escória na correção de acidez do solo, observaram baixa eficiência da escória de siderurgia, com base no PN adotado para o calcário. O teor de potássio foi maior no solo que recebeu escória silicatada. O contrário ocorreu com o magnésio, pois houve acréscimo em seu teor no solo corrigido com calcário. O teor de cálcio não diferiu entre os corretivos (Tabela 1).

As variáveis $\mathrm{pH}, \mathrm{Ca}, \mathrm{Mg}$ e $\mathrm{H}+\mathrm{Al}$ foram significativas em relação ao fator dose, independentemente do corretivo, ajustando-se respectivamente às equações lineares $\mathrm{y}$ $=4,708+0,038 x, y=12,425+0,750 x, y=8,837+0,380 x$ e $y=36,037-0,516 x$, com coeficientes de regressão significativos a $1 \%$. No entanto, verificou-se aumento no teor de magnésio no solo em função do aumento das doses de calcário e escória silicatada, ajustando-se, respectivamente, às equações lineares $y=8,825+0,563 x$ e y $=8,850+0,197 x$, com coeficientes de regressão lineares significativos a $1 \%$ (Figura 2). Esse aumento de magnésio pode ser explicado devido ao calcário possuir maior quantidade de $\mathrm{MgO}$ em relação à escória silicatada.

Na primeira contagem do número de perfilhos observou-se efeito significativo para a variável corretivo (Tabela 2), obtendo-se maior número de perfilhos quando foi aplicada a escória silicatada. Esse mesmo efeito foi observado na segunda contagem do número de perfilhos, em que verificou-se aumento dos perfilhos na dose de 1,5 


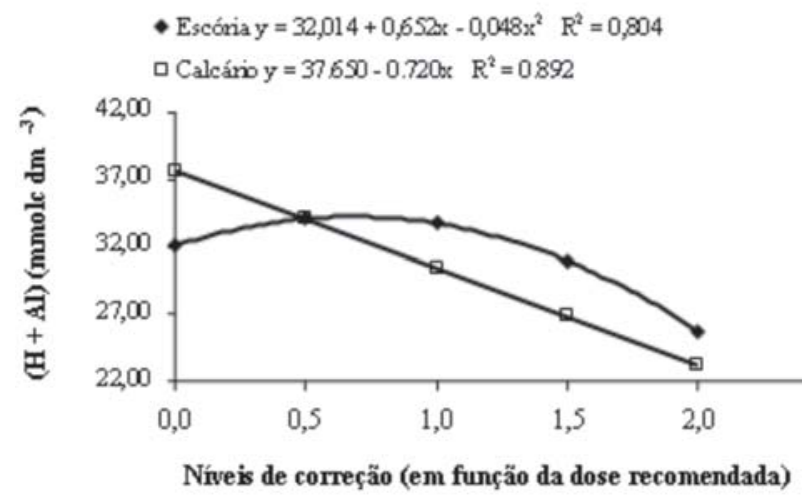

Figura 1. Acidez potencial $(\mathrm{H}+\mathrm{Al})$ do solo em razão dos níveis de correção com calcário e escória silicatada.

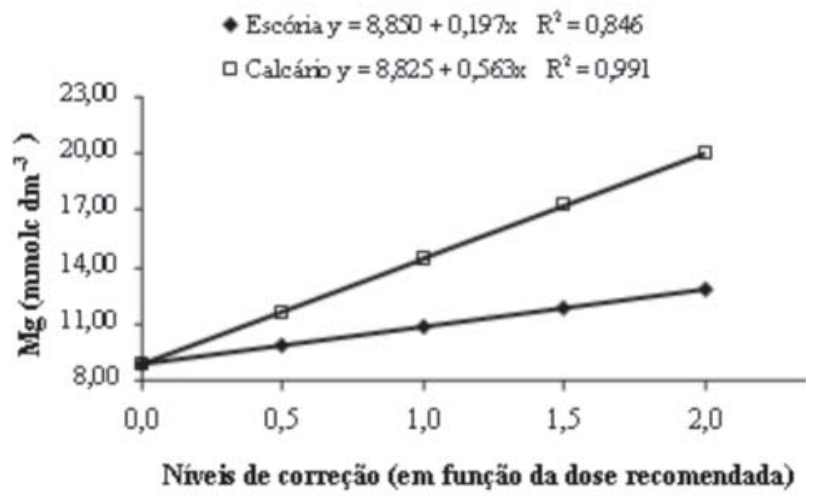

Figura 2. Magnésio no solo em razão dos níveis de correção com calcário e escória silicatada.

Tabela 1. Atributos químicos do solo antes e após a sua correção de acidez

\begin{tabular}{lccccc}
\hline \multirow{2}{*}{ Fatores } & \multicolumn{5}{c}{ Variáveis } \\
\cline { 2 - 5 } & $\mathbf{p H}$ & $\mathbf{K}$ & $\mathbf{C a}$ & $\mathbf{M g}$ & $\mathbf{H}+\mathbf{A l}$ \\
\hline & & & $\mathrm{mmol}_{\mathrm{c}} \mathrm{dm}^{-3}$ & & $30,4 \mathrm{a}$ \\
Calcário & $5,2 \mathrm{a}$ & $2,2 \mathrm{~b}$ & $18,7 \mathrm{a}$ & $14,5 \mathrm{a}$ & $31,3 \mathrm{a}$ \\
Escória silicatada & $5,0 \mathrm{~b}$ & $2,4 \mathrm{a}$ & $21,2 \mathrm{a}$ & $10,8 \mathrm{~b}$ & \\
\hline
\end{tabular}

Médias seguidas de mesma letra, na coluna, não diferem entre si pelo teste de Tukey a 5\%.

Tabela 2 - Valores de F e coeficiente de variação dos números de perfilhos

\begin{tabular}{lcccccccc}
\hline Causas de & \multicolumn{9}{c}{ Valores de F } \\
Variação & $\mathbf{P}_{\mathbf{1}}{ }^{\mathbf{1}}$ & $\mathbf{P 2}$ & $\mathbf{P 3}$ & $\mathbf{P 4}$ & $\mathbf{P 5}$ & $\mathbf{P 6}$ & $\mathbf{P 7}$ & $\mathbf{P 8}$ \\
\hline Corretivo & $4,83^{*}$ & 0,49 & 1,56 & 0,42 & 0,86 & 1,20 & 1,04 & 0,76 \\
Doses & 0,68 & 0,35 & 0,40 & 0,34 & 2,38 & 2,03 & 1,16 & 0,82 \\
Corretivo x doses & 1,85 & $3,46 *$ & 1,20 & 0,37 & $3,37 *$ & 1,74 & 0,60 & 0,96 \\
CV(\%) & 26,71 & 22,6 & 13,90 & 17,60 & 11,8 & 13,6 & 19,53 & 21,61 \\
\hline
\end{tabular}

** e * Significativos a 1 e $5 \%$, respectivamente, pelo teste $\mathrm{F}$.

Cortes do capim aos 51, 87 e 112 dias após a germinação.

${ }^{1}$ Contagens de perfilhos aos 18, 25, 32, 39, 46, 71, 93 e 119 dias após a germinação.

vezes a dose recomendada apenas para a escória silicatada (Figura 3).

O número de perfilhos da quinta contagem para o corretivo calcário em função das doses apresentou maior número a partir da aplicação de 1,0 vez a dose recomendada, ajustando-se à equação quadrática $\mathrm{y}=12,477-0,455 \mathrm{x}+$ $0,020 x^{2}$ (Figura 4). No entanto, para a escória silicatada ajustou-se à equação cúbica $\mathrm{y}=10,148+0,634 \mathrm{x}-0,098 \mathrm{x}^{2}+$ $0,003 \mathrm{x}^{3}$, havendo maior perfilhamento com 2,0 vezes a dose recomendada.

O maior teor de proteína foi observado no terceiro corte com a aplicação de escória silicatada correspondente à dose recomendada (Tabela 3).

Os teores médios das variáveis matéria seca, proteína, FDN e FDA encontram-se na Tabela 2. Verifica-se que o teor de matéria seca foi maior no terceiro corte, variando de 12,18 g vaso $^{-1}$ (1,5 vezes a dose recomendada de calcário) a 15,59 g vaso $^{-1}$ (1,0 vez a dose recomendada de escória). Analisando o teor de proteína, observa-se que o valor decresceu a cada corte realizado, concordando com os resultados obtidos por Costa et al. (2007), os quais observaram que o aumento no intervalo de corte refletiu em menor teor de proteína. Esse fato deve estar relacionado ao estádio de desenvolvimento da planta, visto que forragens mais maduras apresentam baixa proporção de carboidratos solúveis, carboidratos de baixa digestibilidade e aumento de proporção de lignina, celulose, hemicelulose e outras frações indigestíveis.

A correção do solo, independentemente do tipo de corretivo, tendeu a aumentar os teores médios de matéria seca (Tabela 3), porém estatisticamente não apresentou diferença em função dos tipos e doses dos corretivos. Soares Filho (1991), em experimento com braquiária submetida à incorporação de calcário com grade aradora também não encontrou efeito significativo sobre a produção de matéria seca.

A composição bromatológica da braquiária, avaliada pelos teores de FDN e FDA, não foi afetada pelos correti- 
Tabela 3. Teores médios das variáveis matéria seca, proteína, FDN e FDA

\begin{tabular}{|c|c|c|c|c|c|c|c|c|c|c|c|c|}
\hline \multirow[b]{2}{*}{ Tratamentos } & $\mathrm{MS}^{1}$ & $\mathrm{MS}^{2}$ & $\mathrm{MS}^{3}$ & Proteína ${ }^{1}$ & Proteína $^{2}$ & Proteína $^{3}$ & $\mathrm{FDN}^{1}$ & $\mathrm{FDN}^{2}$ & $\mathrm{FDN}^{3}$ & $\mathrm{FDA}^{1}$ & $\mathrm{FDA}^{2}$ & $\mathrm{FDA}^{3}$ \\
\hline & \multicolumn{3}{|c|}{ (gramas vaso $^{-1}$ ) } & \multicolumn{9}{|c|}{$(\%)$} \\
\hline Test. & 11,13 & 12,08 & 13,02 & 9,15 & 6,51 & 5,70 & 58,68 & 60,91 & 61,63 & 29,51 & 27,78 & 28,61 \\
\hline $\mathrm{E} / 0,5$ & 12,95 & 12,87 & 13,48 & 10,98 & 7,84 & 5,80 & 60,05 & 60,26 & 60,73 & 30,25 & 27,97 & 28,40 \\
\hline $\mathrm{E} / 1,0$ & 12,30 & 12,25 & 15,59 & 10,85 & 7,86 & 6,45 & 60,13 & 58,39 & 62,41 & 30,99 & 27,40 & 29,89 \\
\hline $\mathrm{E} / 1,5$ & 9,66 & 9,95 & 14,10 . & 9,22 & 7,93 & 5,60 & 60,39 & 58,66 & 61,84 & 30,57 & 27,39 & 25,75 \\
\hline $\mathrm{E} / 2,0$ & 9,54 & 12,16 & 14,02 & 11,07 & 7,54 & 5,44 & 59,01 & 59,84 & 60,90 & 31,02 & 27,74 & 28,62 \\
\hline Test. & 10,50 & 12,26 & 13,40 & 11,03 & 7,21 & 5,69 & 59,49 & 59,65 & 62,65 & 31,15 & 28,59 & 30,05 \\
\hline $\mathrm{C} / 0,5$ & 13,34 & 11,13 & 15,23 & 10,70 & 7,58 & 5,89 & 55,68 & 59,29 & 60,80 & 26,88 & 27,15 & 28,57 \\
\hline $\mathrm{C} / 1,0$ & 10,61 & 11,11 & 14,41 & 10,88 & 7,81 & 5,09 & 58,59 & 58,66 & 61,77 & 29,98 & 26,94 & 29,95 \\
\hline $\mathrm{C} / 1,5$ & 12,51 & 10,77 & 12,18 & 11,23 & 7,42 & 4,92 & 60,27 & 60,40 & 59,07 & 30,66 & 27,73 & 28,21 \\
\hline $\mathrm{C} / 2,0$ & 12,40 & 13,47 & 13,45 & 10,89 & 7,97 & 6,01 & 58,13 & 58,80 & 63,56 & 30,08 & 27,33 & 25,24 \\
\hline
\end{tabular}

${ }^{1}$ Primeiro corte; ${ }^{2}$ Segundo corte; ${ }^{3}$ Terceiro corte; E: Escória silicatada, C: Calcário.

Perfilhamento 2

$\multimap$ - escória $\mathrm{y}=2,636-0,3935 \mathrm{x}+0,054 \mathrm{x}^{2}-0,002 \mathrm{x}^{3} \quad \mathrm{R}^{2}=0,9821 * *$

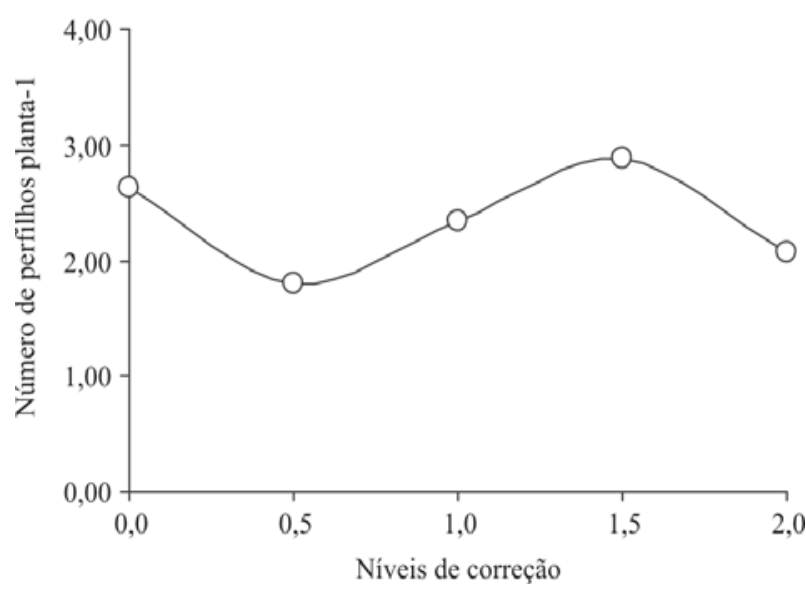

Figura 3. Número de perfilhos em razão dos níveis de correção com escória silicatada.

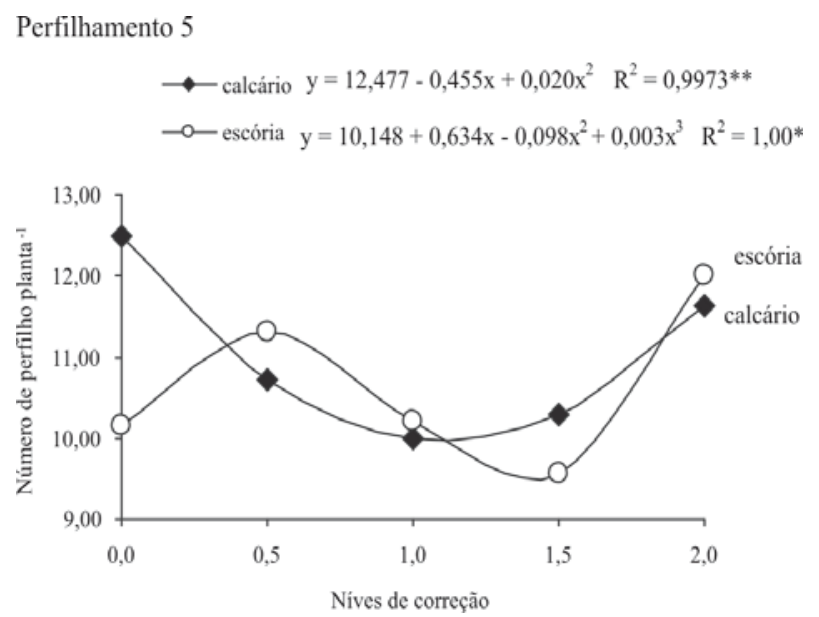

Figura 4. Número de perfilhos em razão dos níveis de correção com calcário e escória silicatada. vos de acidez, exceto no terceiro corte, em que a aplicação de calcário proporcionou maior teor de FDN em relação à escória silicatada. O uso de calcário, além de corrigir a acidez do solo, fornece cálcio às plantas, o que pode fortalecer a estrutura da parede celular, tornando-a mais resistente à degradação. Os teores médios de FDN aumentaram do primeiro para o terceiro corte, enquanto os de FDA apresentaram comportamento inverso, indicando assim maior proporção de estruturas de menor degradabilidade com o aumento do intervalo de corte.

\section{CONCLUSÕES}

Tanto a escória quanto o calcário proporcionaram aumento do pH do solo, refletindo no aumento da disponibilidade de nutrientes como cálcio e magnésio.

A aplicação de calcário proporcionou maior número de perfilhos nas contagens iniciais, enquanto a aplicação de escória aumentou o número de perfilhos na quinta e sexta contagens.

O capim-braquiária não respondeu em produção de matéria seca e FDA aos tipos e doses de corretivos avaliados.

\section{REFERÊNCIAS}

Amaral AS, Defelipo BV, Costa LM \& Fontes MPF (1994) Liberação de $\mathrm{Zn}, \mathrm{Fe}, \mathrm{Mn}$ e $\mathrm{Cd}$ de quatro corretivos da acidez e absorção por alface em dois solos. Pesquisa Agropecuária Brasileira, 29:1351-1358.

Barbosa Filho MP, Zimmermann, FJP \& Silva OF (2004) Influência da escória silicatada na acidez do solo e na produtividade de grãos do arroz de terras altas. Ciência e Agrotecnologia, 28:323-331.

Cantarella H, Correa LA, Primavesi O \& Primavesi AC (2002) Fertilidade do solo em sistemas intensivos de manejo de pastagens. In: Simpósio sobre manejo da pastagem, Tema: Inovações tecnológicas no manejo de pastagens, Piracicaba. Anais, FEALQ. p.99-133. 
Costa KAP, Oliveira IP, Faquin V, Neves BP, Rodrigues C \& Sampaio FMT (2007) Intervalo de corte na produção de massa seca e composição químico-bromatológica de Brachiaria brizantha cv. MG-5. Ciência e Agrotecnologia, 31:1197:1202.

Fageria NK, Filho MPB \& Garber MJ (1982) Nível de nutrientes e densidade de plantio adequados para experimentos com arroz em casa de vegetação. Pesquisa Agropecuária Brasileira, 17:12791284.

Fortes JLO (1993) Eficiência de duas escórias de siderurgia, do Estado do Maranhão, na correção da acidez do solo. Dissertação de Mestrado. Universidade Federal de Viçosa, Viçosa. 66p.

Kissmann KG (1997) Plantas infestantes e nocivas. 2 $2^{a}$ ed. São Paulo, Basf Brasileira. 825p.

Malavolta E (1981) Corretivos cálcicos, magnesianos e calcomagnesianos. In: Malavolta E (Ed.) Manual de química agrícola: adubos e adubação. São Paulo, Agronômica Ceres. p.232245.

Mesquita EE, Fonseca DM, Nascimento Junior D, Pereira OG \& Pinto JC (2002) Efeitos de Métodos de Estabelecimento de Braquiária e Estilosantes e de Doses de Calcário, Fósforo e Gesso sobre Alguns Componentes Nutricionais da Forragem. Revista Brasileira de Zootecnia, 31:2186-2196.

Oliveira PPA, Trivelin PCO \& Oliveira \& WS (2007) Balanço de nitrogênio $\left({ }^{15} \mathrm{~N}\right)$ da uréia nos componentes de uma pastagem de capim-marandu sob recuperação em diferentes épocas de calagem. Revista Brasileira de Zootecnia, 36:1982-1989.

Pereira JE (1978) Solubilidade de alguns calcários e escórias de alto-forno. Dissertação de Mestrado. Universidade Federal de Viçosa, Viçosa. 84p.

Piau WC (1995) Efeitos de escórias de siderurgia em atributos químicos de solos e na cultura do milho (Zea mays L.). Tese de Doutorado. Centro de Energia Nuclear na Agricultura, Universidade de São Paulo, Piracicaba. 124p.
Prado RM \& Fernandes FM (2000) Escória de siderurgia e calcário na correção da acidez do solo cultivado com cana de açúcar em vaso. Sciencia Agrícola, 57:739-744.

Prado RM \& Fernandes FM (2000) Eficiência da escória de siderurgia em areia quartzosa na nutrição e na produção de matéria seca de cana-de-açúcar cultivada em vaso. STAB Açúcar, Álcool e Subprodutos, 18:36-39.

Prado RM (2000) Resposta da cana-de-açúcar à aplicação de escória silicatada como corretivo de acidez do solo. Dissertação de Mestrado. Universidade Estadual Paulista “Júlio de Mesquita Filho”, Ilha Solteira. 52p.

Raij, B. van \& Quaggio JA (1983) Métodos de análise de solo. Campinas, Instituto Agronômico. 31p. (Boletim técnico, n.81).

Soares Filho CV (1991) Variação sazonal de parâmetros bioquímicofisiológicos em Brachiaria decumbens estabelecida em pastagem. Dissertação de Mestrado. ESALQ, Piracicaba. 110p.

Souza E \& Yasuda M (1994) Uso agronômico do termofosfato no Brasil. São Paulo, Fertilizantes Mitsui. 60p.

Veloso CAC (1992) Efeito de diferentes materiais no $\mathrm{pH}$ do solo. Disponível em: http://www.scielo.br/ scielo.php?script=sci_arttext\&pid=S010390161992000400016\&lng=pt\&nm=iso>. Acessado em: 27 de julho de 2007.

Vilela H, Andrade RA \& Vilela D (2007) Efeito níveis de Silmag (Silicato) sobre correção do solo, produção e valor nutritivo Capim Elefante Paraíso (Pennisetum hybridum). Agronomia o portal da ciência e tecnologia. Disponível em: <http:// w w w . a gronomia . com.br/conteudo/a r tigos/ artigos_efeitos_niveis_silmag.htm $>$ Acessado em: 6 de marco de 2010 .

Werner CJ, Paulino VT, Cantarella H, Quaggio JA \& Andrade NO (1997) Forrageiras. In: RAIJ, B. van (Ed.). Recomendações de adubação e calagem para o estado de São Paulo. $2^{\mathrm{a}}$ ed. Campinas, IAC, p.285. (Boletim Técnico, 100). 